\title{
Cardiac Tamponade
}

National Cancer Institute

\section{Source}

National Cancer Institute. Cardiac Tamponade. NCI Thesaurus. Code C50481.

Acute compression of the heart caused by increased intrapericardial pressure due to the collection of blood or fluid in the pericardium from rupture of the heart, penetrating trauma, or progressive effusion. 